\title{
Effect of Cardiopulmonary Resuscitation (CPR) Training program on knowledge and practices of Internship Technical Institute of nursing students
}

\author{
Eman A. Mohamed \\ Lecturer of Pediatric Nursing, Faculty of Nursing, South Valley University- Egypt
}

\begin{abstract}
Background: Cardiopulmonary resuscitation students are expected to be proficient in their clinical skills at graduation to improving patient outcomes.

Aim: To assess the effect of cardiopulmonary resuscitation (CPR) training program on knowledge and practices of internship technical institute of nursing students.

Design: Pre-posttest research design was used in this study.

Setting: This study was conducted at technical institute of nursing, South Valley University, Qena city. Subjects: A convenient sample of all internship technical institute of nursing student (44) were included in the study. Tool: A self-administered questionnaire sheet and observational checklist were used.

Results: The mean CPR knowledge score of students was $9.66 \pm 2.92$ before the training, which increased to $23.52 \pm 2.98$ one month after the CPR training $(p<0.000 *)$. Mean practices scores of the students of the CPR training were $3.32 \pm 2.04$, which increased to $10.09 \pm 1.03$ after one month's post program $(p<0.000 *$ ). Conclusion: Nursing students were improving in level of knowledge and practices regarding CPR after training program.

Recommendations: Nursing curriculum should play more emphasis on the nurses to learn about different techniques of CPR. Continuing education should be conducted on regular after employment to prevent the loss of knowledge and practices.
\end{abstract}

Key words: Cardiopulmonary resuscitation, nursing, student, program.

\section{Introduction}

The emergency nursing role in Africa is identified as particularly challenging secondary to high staff turn-over rates, limited specialty training, and highly stressful patient care environments (London et al., 2001; Bergman et al., 2008; Hardcastle and Oteng, 2011). Patients presenting to Accident and Emergency Centers (A\&E) with acute medical illness or traumatic injury require nursing and physician providers should skilled in triage, acute resuscitation and parallel team-oriented interventions (Wolf et al., 2012, Anne et al., 2014).

Cardiac arrest is a major public health problem affecting thousands of individuals each year in both out-of-hospital and in-hospital settings (Sutton et al., 2012). In 2012 nearly 383,000 out-of-hospital sudden cardiac arrests occurred and approximately 209,000 cardiac arrests occurred within a hospital (American Heart Association, 2013). Survival rates from cardiac arrest are improving, however overall rates of survival are still low (American Heart Association, 2013).

Cardiopulmonary resuscitation (CPR) knowledge in relation to standard care is fundamental in effective resuscitation performance. However, the existing literature has shown that the quality of CPR among nurses and nursing students is inferior to the standards of care (M€akinen et al., 2010; Oermann et al., 2011; Roh and Issenberg, 2014).

CPR is an essential skill required by nursing students for clinical practice, as nurses are frequently first responders in hospital code situations (Kardong-Edgren, et al., 2010). Studies document that CPR skills among nursing students are lacking (Mäkinen et al., 2010; Oermann et al., 2011).

Nurse educators prepare nurses to practice in complex and dynamic healthcare environments. Students graduating from nursing schools around the country often feel unprepared to meet the demands placed on them by the healthcare industry (Benner et al., 2010).

Nursing students need to successfully complete a CPR course prior to entry into a nursing program or before beginning their clinical experiences. While many studies on CPR training and retention of skills have been done with physicians, nurses, emergency medical services personnel, and lay persons, there is limited research on CPR training for nursing students. In one study, students acquired CPR knowledge and skill following Instructor - led (IL) training when compared to pretest, but they could not pass the CPR skills assessment at any point during the research. The researchers speculated that their findings indicated a lack of initial skill acquisition rather than retention. Other studies have documented that nursing students could not 
perform the basic steps of CPR in a simulation setting even though they had completed training course (Kardong-Edgrena (2010) Kardong-Edgren \& Adamson (2009).

The curriculum not included the Cardiopulmonary resuscitation in the Institute of nursing. The nursing curriculum should play more emphasis on the nurses to learn about different techniques of CPR. This is essential for working in hospital settings.

Cardiopulmonary resuscitation students are expected to be proficient in their clinical skills at graduation; those more confident in their skills and knowledge tend to perform effectively in clinical settings, thus improving patient outcomes. The students attending Cardiopulmonary resuscitation course at a south valley university have limited exposure to life threatening situations (or simulations of the same) that would allow them to fully learn and utilize their CPR skills.

\section{Aim Of Study}

To assess the effect of cardiopulmonary resuscitation (CPR) training program on knowledge and practices of internship technical institute of nursing students.

\section{Research Hypothesis}

$\mathbf{H}_{\mathbf{1}}$. There will be a significant difference between pre-test and post-test scores of knowledge and skill levels of nursing students regarding cardio-pulmonary resuscitation.

$\mathbf{H}_{2}$. There will be significant association between knowledge and skill levels of nursing students regarding cardio-pulmonary resuscitation and selected socio demographic variables.

\section{Subjects And Methods}

4.1 Design: Pre-posttest research design was used in this study.

4.2 Setting: This study was conducted at technical institute of nursing, South Valley University, Qena city.

4.3 Subjects: A convenient sample of all internship technical institute of nursing students were 44students included in the study.

4.4 Tool of data collection:

Tool of data collection in this study includes the following:

Socio demographic data:

Include subject's age, residence, marital status, academic performance.

Knowledge Assessment Form:

This form was developed by Aruna C.G. (2012). It composed of 28 multiple-choice questions regarding the participants' knowledge about CPR. it included information about introduction, definition, techniques of CPR at various age group and steps in CPR. The same questionnaire was distributed before the knowledge and then one month after. Each correct answer in the questionnaire was assigned one point, and the students were assessed with a score out of 28

Scoring: The structured questionnaire contains 28 items. It can be scored as right answer -1 wrong answer -0 Maximum possible score is 30 and the minimum is 0. Level of knowledge: Inadequate $\leq 50 \%$ Moderate $51-75 \%$ adequate $\geq 75 \%$

\section{Practice Assessment Form:}

This form was developed by (Madden 2006). It composed of 11 steps, including the steps of CPR application. These steps include skills such as finding an appropriate position in order to ensure that the airway is open, finding an appropriate position to chest compression, and applying appropriate pressure. The skills of the students were assessed by observing their application of CPR on the infant manikin.

The skills assessment form was applied one month (posttest) after each student completed the applied training. The students were taken to the application by the researcher one by one and their performances using the CPR model were observed. Each correct skill on the application form was assigned one point, and the students were assessed using a score out of 11 .

Scoring: The structured Checklist contains 11 items. It can be scored as right answer - 1 Wrong answer - 0 Maximum possible score is 11 and the minimum is 0. Level of practice: Inadequate $\leq 50 \%$. Moderate $51-75 \%$ adequate $\geq 75 \%$

\section{Designing the educational program:}

The designed educational program regarding CPR was developed and constructed by the researcher in the form of booklet. The booklet consisted of Definition, indication, purpose, different techniques used in different age group, steps used in CPR and complication.

\subsection{Pilot study}

Pilot study was carried from in institute of nursing at south valley university after obtaining permission from the concerned authority and got written consent from student nurses. No changes were made in the study design after the pilot study. 


\section{Reliability:-}

To ensure reliability assessment tool is giving to participants on two separate occasions. The same results were obtained Cronbach's coefficient alpha was $(0.74)$

\section{Validity:-}

Validity refers to how well a test measures what it is purported to measure. To achieve validity five experts in the field of nursing were selected to evaluate the content validity of the tool. Their suggestions and modifications were taken in consideration.

\subsection{Ethical Considerations}

A written initial approval obtained from the research ethical committee of the institute of nursing, South Valley University. The researcher explained to students the aim of the study and informed that the information obtained would be confidential and only for the purpose of the study.

\section{Statistical Analysis of data:}

Data were analyzed using statistical package for social sciences (SPSS) version 20. Data were presented using descriptive statistics in the form of frequencies. Quantitative data were presented by mean and standard deviation. A significance level was considered at $\mathrm{P}<0.05$.

\section{Results}

Table (1): Personal characteristics of the studied nursing students

\begin{tabular}{|l|l|l|}
\hline Items & No. $(\mathbf{n}=\mathbf{4 4})$ & \% \\
\hline Age: & \multicolumn{2}{|l|}{} \\
\hline $19-21$ years & 30 & 68.2 \\
\hline$>21$ years & 14 & 31.8 \\
\hline Mean \pm SD (Range) & $21.09 \pm 0.83(20.0-23.0)$ & \\
\hline Residence: & \multicolumn{2}{|l|}{} \\
\hline Rural & 27 & 61.4 \\
\hline Urban & 17 & 38.6 \\
\hline Marital status: & \multicolumn{2}{|l|}{} \\
\hline Married & 6 & 13.6 \\
\hline Unmarried & 38 & 86.4 \\
\hline
\end{tabular}

Fig. (1): Academic performance

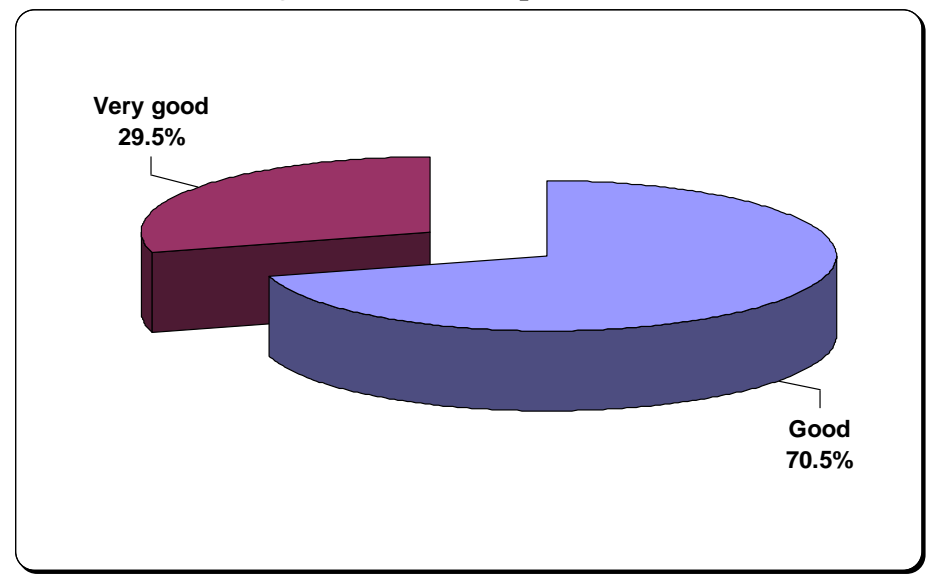

Table (2): Distribution of the correct answers provided by the students regarding CPR before and after being taught CPR

\begin{tabular}{|c|c|c|c|c|c|c|c|c|c|}
\hline \multirow[t]{3}{*}{ Items } & \multicolumn{4}{|c|}{$\begin{array}{l}\text { Pre-test } \\
(n=44)\end{array}$} & \multicolumn{4}{|c|}{$\begin{array}{l}\text { Post-test } \\
(n=44)\end{array}$} & \multirow[t]{3}{*}{ P-value } \\
\hline & \multicolumn{2}{|c|}{ Incorrect } & \multicolumn{2}{|c|}{ Correct } & \multicolumn{2}{|c|}{ Incorrect } & \multicolumn{2}{|c|}{ Correct } & \\
\hline & No. & $\%$ & No. & $\%$ & No. & $\%$ & No. & $\%$ & \\
\hline 1- What is meant by CPR & 39 & 88.6 & 5 & 11.4 & 0 & 0.0 & 44 & 100.0 & $0.000^{*}$ \\
\hline 2-Which of the following is CPR techniques? & 13 & 29.5 & 31 & 70.5 & 1 & 2.3 & 43 & 97.7 & $0.000^{*}$ \\
\hline 3-CPR can perform in & 29 & 65.9 & 15 & 34.1 & 0 & 0.0 & 44 & 100.0 & $0.000^{*}$ \\
\hline 4-Effective CPR will restore and maintain & 20 & 45.5 & 24 & 54.5 & 5 & 11.4 & 39 & 88.6 & $0.000^{*}$ \\
\hline 5-What do you mean EMS? & 13 & 29.5 & 31 & 70.5 & 1 & 2.3 & 43 & 97.7 & $0.000^{*}$ \\
\hline $\begin{array}{l}\text { 6- The most common cause of cardio pulmonary } \\
\text { arrest }\end{array}$ & 14 & 31.8 & 30 & 68.2 & 19 & 43.2 & 25 & 56.8 & 0.271 \\
\hline 7-What is cardiac arrest? & 43 & 97.7 & 1 & 2.3 & 30 & 68.2 & 14 & 31.8 & $0.000^{*}$ \\
\hline 8-Age group can be considered as infant & 11 & 25.0 & 33 & 75.0 & 9 & 20.5 & 35 & 79.5 & 0.611 \\
\hline 9-Age group we can considered as child & 7 & 15.9 & 37 & 84.1 & 1 & 2.3 & 43 & 97.7 & 0.058 \\
\hline 10-CPR technique you will use in an infant if there & 37 & 84.1 & 7 & 15.9 & 6 & 13.6 & 38 & 86.4 & $0.000^{*}$ \\
\hline
\end{tabular}


Effect of Cardiopulmonary Resuscitation (CPR) Training program on knowledge and practices of

\begin{tabular}{|c|c|c|c|c|c|c|c|c|c|}
\hline is one rescuer & & & & & & & & & \\
\hline $\begin{array}{l}\text { 11-Which of the following is the preferred chest } \\
\text { compression technique for } 2 \text {-rescuer CPR in child }\end{array}$ & 44 & 100.0 & 0 & 0.0 & 10 & 22.7 & 34 & 77.3 & $0.000 *$ \\
\hline 12-Techniques of CPR & 43 & 97.7 & 1 & 2.3 & 5 & 11.4 & 39 & 88.6 & $0.000 *$ \\
\hline 13-Depth of compression in infant & 21 & 47.7 & 23 & 52.3 & 0 & 0.0 & 44 & 100.0 & $0.000 *$ \\
\hline 14-Depth of compression in children & 19 & 43.2 & 25 & 56.8 & 2 & 4.5 & 42 & 95.5 & $0.000 *$ \\
\hline $\begin{array}{l}\text { 15-Indication for efficient mouth to mouth } \\
\text { respiration }\end{array}$ & 40 & 90.9 & 4 & 9.1 & 11 & 25.0 & 33 & 75.0 & $0.000 *$ \\
\hline 16-Site you will select for compression & 12 & 27.3 & 32 & 72.7 & 9 & 20.5 & 35 & 79.5 & 0.453 \\
\hline 17-CPR must be performed within & 35 & 79.5 & 9 & 20.5 & 6 & 13.6 & 38 & 86.4 & $0.000 *$ \\
\hline $\begin{array}{l}\text { 18-What you will do if a child collapsed in front of } \\
\text { you? }\end{array}$ & 28 & 63.6 & 16 & 36.4 & 9 & 20.5 & 35 & 79.5 & $0.000 *$ \\
\hline 19-The rate of compression & 18 & 40.9 & 26 & 59.1 & 5 & 11.4 & 39 & 88.6 & $0.002 *$ \\
\hline 20-How you will open the airway of the child? & 15 & 34.1 & 29 & 65.9 & 7 & 15.9 & 37 & 84.1 & $0.000 *$ \\
\hline 21-What you will do for respiratory arrest? & 35 & 79.5 & 9 & 20.5 & 14 & 31.8 & 30 & 68.2 & $0.000 *$ \\
\hline 22-In CAB "C" for & 40 & 90.9 & 4 & 9.1 & 6 & 13.6 & 38 & 86.4 & $0.000 *$ \\
\hline 23-The important complication of CPR & 40 & 90.9 & 4 & 9.1 & 21 & 47.7 & 23 & 52.3 & $0.000^{*}$ \\
\hline $\begin{array}{l}\text { 24-the compression to ventilation ratio for } 1 \text { - } \\
\text { rescuer CPR is }\end{array}$ & 32 & 72.7 & 12 & 27.3 & 9 & 20.5 & 35 & 79.5 & $0.000 *$ \\
\hline 25-Which one is the correct step? & 44 & 100.0 & 0 & 0.0 & 0 & 0.0 & 44 & 100.0 & $0.000 *$ \\
\hline $\begin{array}{l}\text { 26-to reduce rescuer fatigue during CPR } \\
\text { compressor roles should be switched about every }\end{array}$ & 29 & 65.9 & 15 & 34.1 & 8 & 18.2 & 36 & 81.8 & $0.000^{*}$ \\
\hline 27-After each cycle of compression recheck & 43 & 97.7 & 1 & 2.3 & 0 & 0.0 & 44 & 100.0 & $0.000 *$ \\
\hline 28After each compression allows? & 43 & 97.7 & 1 & 2.3 & 3 & 6.8 & 41 & 93.2 & $0.000 *$ \\
\hline
\end{tabular}

Figure (2): Mean total knowledge of students about CPR pre and post test

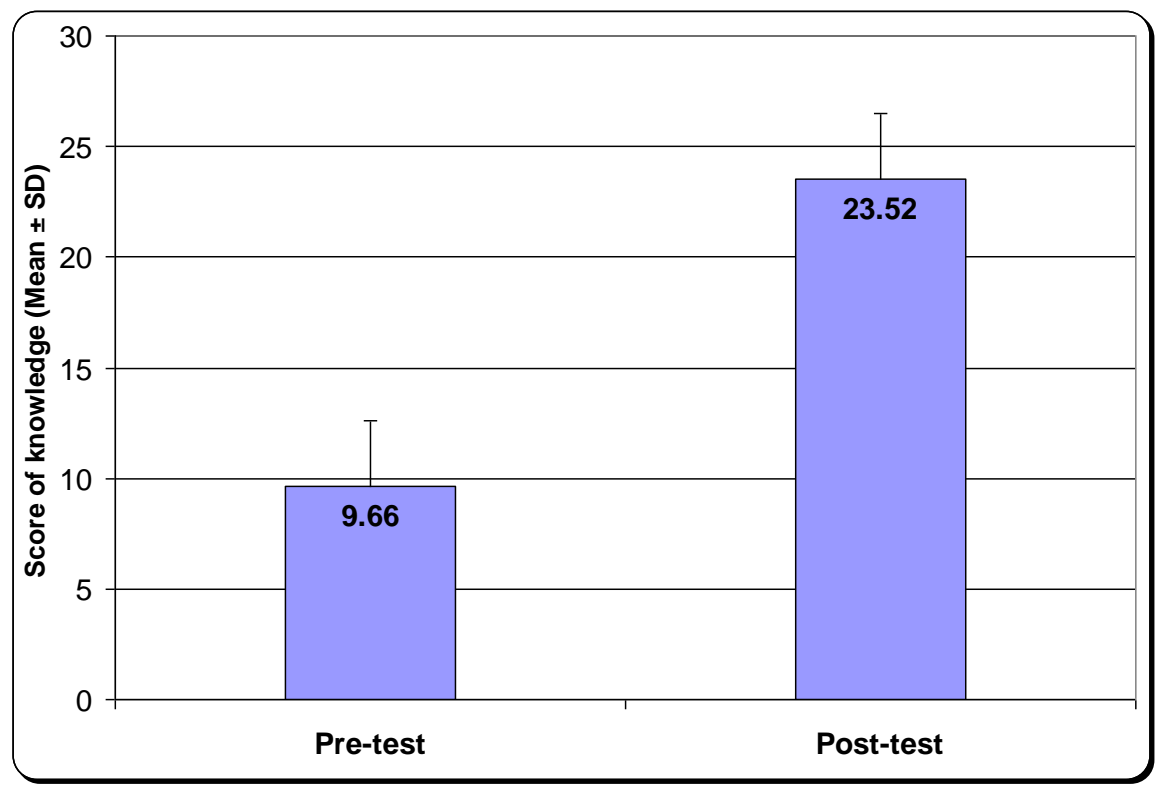

Table (3): Mean total knowledge according to personal characteristics in pre-test and post-test

\begin{tabular}{|c|c|c|c|c|}
\hline \multirow[t]{2}{*}{ Items } & Pre-test & \multirow[t]{2}{*}{ P-value } & Post-test & \multirow[t]{2}{*}{ P-value } \\
\hline & Mean \pm SD & & Mean \pm SD & \\
\hline Age: & & \multirow[t]{3}{*}{0.285} & & \multirow[t]{3}{*}{0.410} \\
\hline $19-21$ years & $9.33 \pm 2.78$ & & $23.27 \pm 3.04$ & \\
\hline$>21$ years & $10.36 \pm 3.20$ & & $24.07 \pm 2.87$ & \\
\hline Residence: & & \multirow[t]{3}{*}{0.771} & & \multirow[t]{3}{*}{0.361} \\
\hline Rural & $9.56 \pm 3.33$ & & $23.85 \pm 3.00$ & \\
\hline Urban & $9.82 \pm 2.21$ & & $23.00 \pm 2.96$ & \\
\hline Marital status: & & \multirow[t]{3}{*}{0.231} & & \multirow[t]{3}{*}{0.194} \\
\hline Married & $11.00 \pm 3.90$ & & $25.00 \pm 3.46$ & \\
\hline Unmarried & $9.45 \pm 2.75$ & & $23.29 \pm 2.87$ & \\
\hline Academic performance: & & \multirow[t]{3}{*}{0.243} & & \multirow[t]{3}{*}{0.194} \\
\hline Good & $9.32 \pm 2.86$ & & $23.90 \pm 2.90$ & \\
\hline Very good & $10.46 \pm 3.04$ & & $22.62 \pm 3.07$ & \\
\hline
\end{tabular}


Table (4): Distribution of the correct skills regarding the application steps of CPR after CPR training.

\begin{tabular}{|c|c|c|c|c|c|}
\hline \multirow[t]{2}{*}{ Steps } & \multicolumn{2}{|c|}{$\begin{array}{l}\text { Pre-test } \\
(n=44)\end{array}$} & \multicolumn{2}{|c|}{$\begin{array}{l}\text { Post-test } \\
(n=44)\end{array}$} & \multirow[t]{2}{*}{ P-value } \\
\hline & No. & $\%$ & No. & $\%$ & \\
\hline 1. Open airway: Head tilt Chin tilt & 17 & 38.6 & 37 & 84.1 & $0.000^{*}$ \\
\hline 2. Check for breathing look listen and feel for $10 \mathrm{~s}$ & 9 & 20.5 & 41 & 93.2 & $0.000^{*}$ \\
\hline 3. Give two slow breaths & 15 & 34.1 & 42 & 95.5 & $0.000^{*}$ \\
\hline 4. $\quad$ Initial pulse check & 8 & 18.2 & 44 & 100.0 & $0.000^{*}$ \\
\hline 5. Correct hand position & 14 & 31.8 & 40 & 90.9 & $0.000^{*}$ \\
\hline 6. $\quad$ Performs 15 compressions & 11 & 25.0 & 38 & 86.4 & $0.000^{*}$ \\
\hline 7. Depth of chest compressions & 13 & 29.5 & 44 & 100.0 & $0.000^{*}$ \\
\hline 8. $\quad$ Release of chest compressions & 21 & 47.7 & 44 & 100.0 & $0.000^{*}$ \\
\hline 9. Give two slow continuing breaths & 16 & 36.4 & 37 & 84.1 & $0.000 *$ \\
\hline 10. Compression to breathing ratio of $15: 2$ & 7 & 15.9 & 36 & 81.8 & $0.000^{*}$ \\
\hline 11. Performs four complete cycles & 15 & 34.1 & 41 & 93.2 & $0.000 *$ \\
\hline
\end{tabular}

Figure (3): Practice perform of nursing students pre and post test.

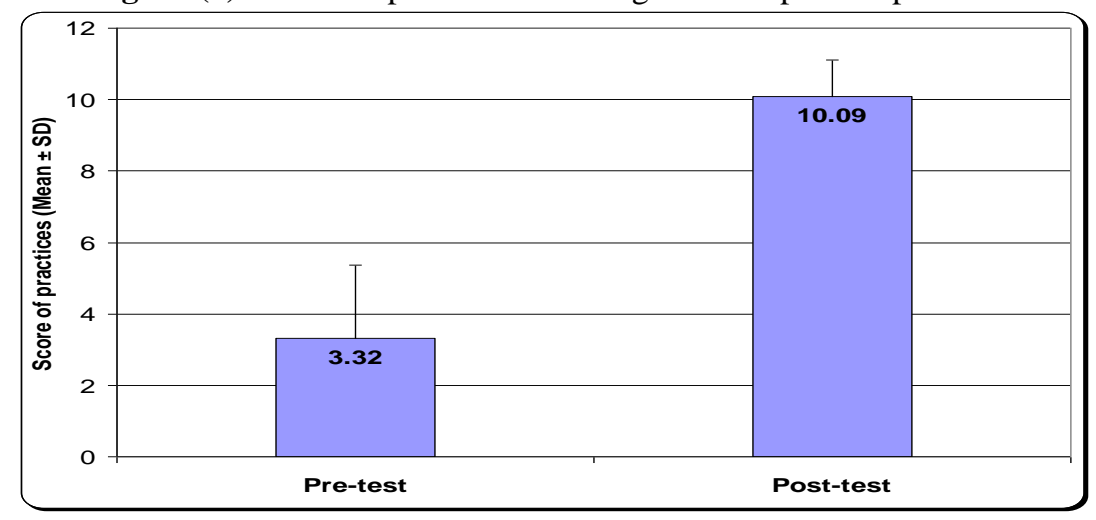

Table (5): Comparison of students' posttest and retest average skill scores.

\begin{tabular}{|c|c|c|c|c|}
\hline & Pre-test & \multirow[t]{2}{*}{ P-value } & Post-test & \multirow[t]{2}{*}{ P-value } \\
\hline & Mean \pm SD & & Mean \pm SD & \\
\hline \multicolumn{2}{|l|}{ Age: } & \multirow[t]{3}{*}{0.540} & & \multirow[t]{3}{*}{0.276} \\
\hline $19-21$ years & $3.20 \pm 2.07$ & & $9.97 \pm 1.10$ & \\
\hline$>21$ years & $3.57 \pm 2.03$ & & $10.36 \pm 0.84$ & \\
\hline \multicolumn{2}{|l|}{ Residence: } & \multirow[t]{3}{*}{0.981} & & \multirow[t]{3}{*}{0.231} \\
\hline Rural & $3.33 \pm 2.13$ & & $9.96 \pm 1.02$ & \\
\hline Urban & $3.29 \pm 1.96$ & & $10.29 \pm 1.05$ & \\
\hline \multicolumn{2}{|l|}{ Marital status: } & \multirow[t]{3}{*}{$0.020^{*}$} & & \multirow[t]{3}{*}{0.927} \\
\hline Married & $5.00 \pm 1.67$ & & $10.17 \pm 0.75$ & \\
\hline Unmarried & $3.05 \pm 1.99$ & & $10.08 \pm 1.08$ & \\
\hline \multicolumn{2}{|l|}{ Academic performance: } & \multirow[t]{3}{*}{$0.011^{*}$} & & \multirow[t]{3}{*}{0.284} \\
\hline Good & $2.84 \pm 1.95$ & & $9.97 \pm 1.11$ & \\
\hline Very good & $4.46 \pm 1.85$ & & $10.38 \pm 0.77$ & \\
\hline
\end{tabular}

Fig. (4): Correlation between score of knowledge and score of practices in pre-test

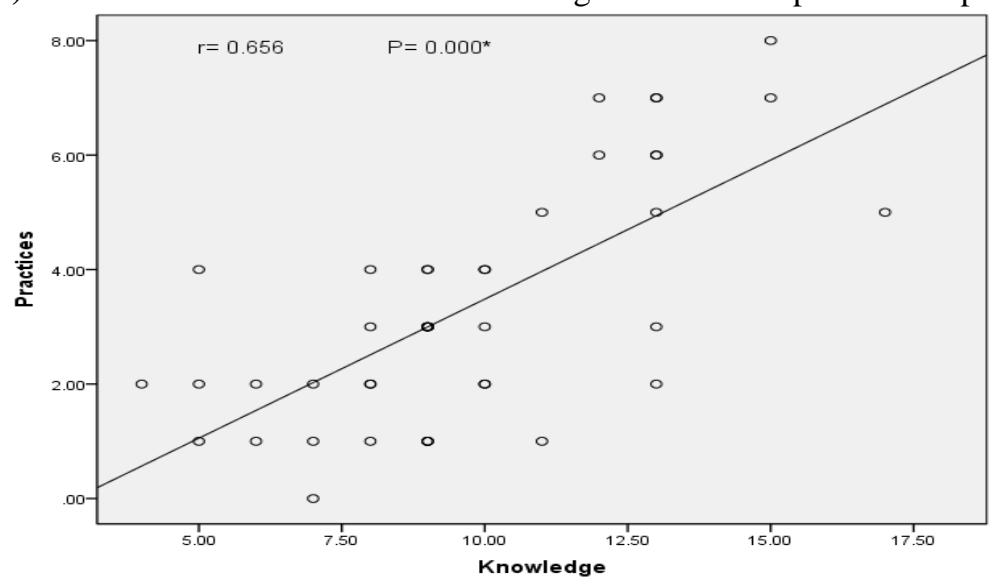


Fig. (5): Correlation between score of knowledge and score of practices in Post-test

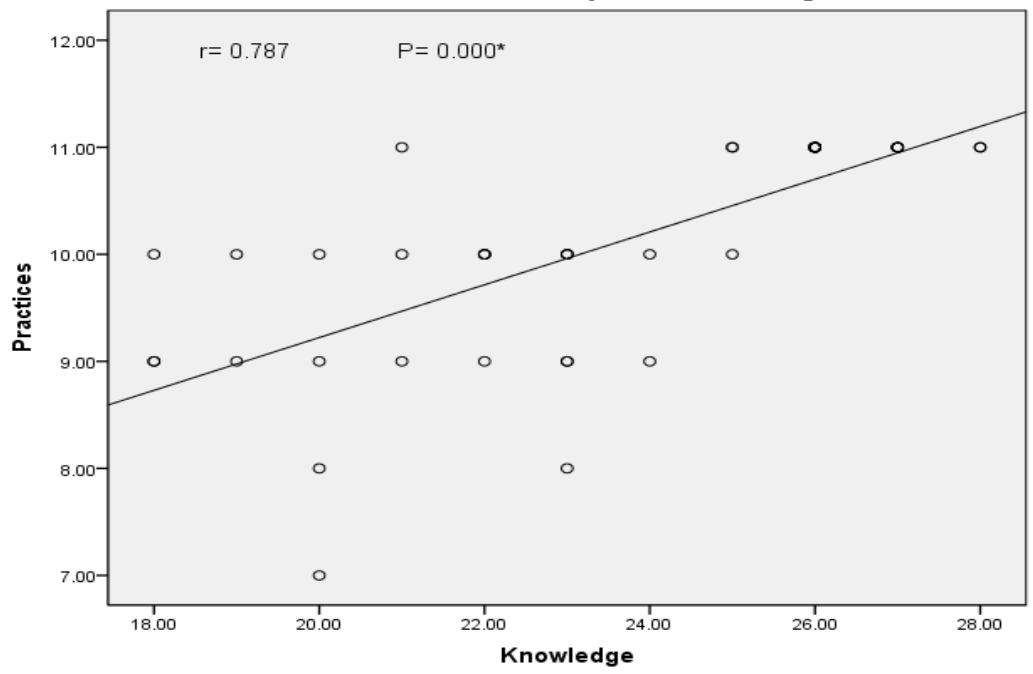

Table (1): Showed that the majority Of nursing students aged from $19-21$ years were (68.2\%), all of them were female $(100 \%)$, from rural area were $(61.4 \%)$, and they were unmarried $(86.4)$

Figure (1): Showed that the majority academic performance of nursing students were good (70.5\%).

Table (2): Show that statistical significant the most of questions of knowledge of students about CPR pre and posttest $P$-value 0.000

Figure (2): Show that the mean total knowledge of students were improved about CPR post test (23.52) while pre-test (9.66).

Table (3): Show that no significant relation between personal characteristics and level of knowledge of nursing students either at the pre or posttest

Table (4) showed that students' skills were improved over their pre-training scores, $P$-value 0.000

Figure (3): Showed that the majority practice perform of nursing students and (mean) were (10.09).compared to 3.32 preprogram.

Table (5): Show that not significant different between Score of practices according to personal characteristics in pre-test and post-test

Figure (4): Show that the positive correlation between score of knowledge and score of practices in pre-test

Figure (5): Show that the positive correlation between score of knowledge and score of practices in Post-test

\section{Discussion}

As nurses are generally the first healthcare professionals to realize that a patient is in cardiac arrest in a hospital, they must have an adequate knowledge of CPR and the relevant skills, Lima et al., (2009), Marzooq \& Lyneham (2009).

Previous studies have emphasized that CPR knowledge and skills reduce over time when they are not repeated and that the level of knowledge and skills of nurses who practice constantly is better than those who do not Oermann et al., (2011) \& Nyman \& Sihvonen ( 2000).

The findings indicated that students lacked CPR cognitive knowledge in the pre-test, and there is statistical increase in the knowledge the most of questions of knowledge of students about CPR. This finding is consistent with previous studies (Broomfield, 1996). Following the CPR training program, there was a significant acquisition in students' CPR cognitive knowledge, which supports the findings of Broomfield (1996); and Madden (2006) findings indicate that students lacked CPR cognitive knowledge in the pre-test, despite the fact that all students received CPR training one year previously.

Shahrakivahed, et al (2015) stated that the average score of nurses' level of knowledge and skill after educational intervention had a significant difference with the average score of their level of knowledge and skill before training $(\mathrm{p}<0.05)$.

Mokhtari Nori et al., (2012) Findings related to the degree of knowledge and psychomotor skills in 4 stages in our study showed that the degree of CPR knowledge and psychomotor skills before training indicate that, technical institute that they lack this part in their syllabus

In this study were lack knowledge and skills before training and acquisition of knowledge and skills of CPR after training. This finding is agreed with Peter et al., report that hospital health care providers (HCP's) at baseline report only $28 \%$ prior formal CPR training, and baseline cognitive knowledge and skills before training 
were poor. Acquisition of knowledge and CPR skills following initial training using modified programs was good, and 100\% reached acquisition of CPR skill competence after training. Excellent infant CPR skills were over 3 times more likely to be performed immediately after training Peter et al., (2012).

Technical nursing students in this study significantly retained both knowledge and skills for one month. This is different than previously reported CPR training literature from developed countries Roppolo et al.(2007), Einspruch et al.(2007), Spooner et al.(2007), and Smith et al.(2008). Rates of CPR knowledge and skill retention were similar to our previous study in a resource-rich, in-hospital environment examining low dose, high-frequency CPR training, but providers in this study retained skills without retraining Sutton et al (2011). In Korea, Na et al. reported a decrease in hands-off time between medical interns at a tertiary hospital evaluated 6 months and 12 months after initial CPR training Na et al (2011).

Motor learning is permanent. Learning a skill means it is retained and able to be performed at a later time. The goal of skill instruction in nursing, as in other health care fields, is to foster learning and transfer of skills to clinical practice. When students practice skills in a laboratory setting, and educators observe and assess their performance, that assessment may not represent actual learning of the skill. For learning to occur, the skill needs to be sufficiently practiced to be retained and transferable (Wulf et al., 2010).

In a study by Yildirim and Celik. (2008), it was found that there were significant differences between the average scores that the nurses achieved on the CPR test depending on when they received CPR training.

The study by Marzooq and Lyneham (2009) showed that nurses wait for their institution to offer basic life support training, instead of considering it as their responsibility to seek it out. Thus, schools and institutions have an important role in terms of planning CPR training.

The students' CPR skills performance, statistical increase in the total mean skills of student after the training program regarding nearly most of the items of skills compared to the pretest. While this finding is disappointing, it is consistent with other studies of nurses' CPR skills (Devlin, 1999). However, this should not be confused with students not learning any new skills. The findings clearly demonstrate a positive training effect and a significant acquisition in psychomotor skills. This study highlighted that all students performed none of the individual CPR skill components competently, which is consistent with the findings of previous studies (Devlin, 1999). These findings differ from Devlin (1999); and Nyman and Sihvonen (2000), who consistently found that chest compressions were the poorest performed skill.

Previous research demonstrated that a simulation group had a significantly higher mean knowledge score posttest than the control group (Liaw et al., 2011). Our results indicate the importance of simulation training for retaining information, which was a key factor for influencing the combination of simulation learning and clinical practice (Liaw et al., 2012).

Previous research demonstrates that simulation-based resuscitation training for healthcare professionals improved their self-efficacy (Turner et al., 2007), and nursing students perceived that simulation increased their ability and confidence in their clinical placements (Baillie \& Curzio, 2009) and successful experiences in resuscitation courses increased perceived self-efficacy (Hunt et al., 2008).

Significantly increased post-intervention, but not compression rate and chest recoil. Previous studies verified that simulation-based resuscitation training had positive effects on the mastery learning of advanced cardiac lifesupport skills in residents (Wayne et al., 2005, Wayne et al., 2006). Although objective monitoring of repetitive practice is not part of this study, we provided feedback on the quality of CPR psychomotor skills and told nursing students to continue practice to improve their skills at posttest.

One nursing study reported that students with simulation training achieved and maintained higher clinical performance scores more quickly than those without simulation. These findings suggest that patient simulation is a valuable addition to the apprenticeship model (Meyer et al., 2011). It can be assumed that when students are personally involved in handling an emergency event, this could lead to experiential learning and a positive impact on students' motivation (Pelaccia et al., 2009). However, it can be argued that traditionally, clinical education is insufficient if the goal is skill acquisition and downstream patient safety (McGaghie et al., 2011) due to limited simulation realism (McKenna et al., 2011). We suggest the curriculum should be included the Cardiopulmonary resuscitation in the Institute of nursing. The nursing curriculum should lay more emphasis on the nurses to learn about different techniques of CPR. This is essential for working in hospital settings.

It is clear from the results of this study that the majority of age nursing students ranged from $19-21$ years were $(68.2 \%)$, all of them were female $(100 \%)$, were from rural area, were unmarried (38.6\%) and the academic performance were good( $70.5 \%$ ) while very good were ( $29.5 \%$ ). Roh Y S, \& Issenberg B.(2014) found that $91 \%$ of the participants were women. The mean age of the participants was $21.81 \pm 4.52$ years.

In a study among undergraduate nursing students that equally employed quasi experimental time series design (pre-test, CPR training programme, post-test and retest phases) reported by Madden (2006) showed that students' knowledge and skills were improved over their pre-training scores, which clearly indicated positive retention in CPR cognitive knowledge and psychomotor skills those who agreed with your results on tables 2, 3,5 , and 7 . 
Also, in this present study, the observed difference in gender was not statistically significant. In all, gender was not a predicting factor for acquiring CPR knowledge. This finding is in agreement with Miro et al. (2008) who carried out a study in Spain describing 5-year experience of providing training in basic cardiopulmonary resuscitation (CPR) for students in Spanish obligatory secondary school education, including the percentage of satisfactory learning immediately after training and one year later. In their analysis of factors associated with satisfactory learning, they found out that gender was not one of the predictors of learning.

\section{Conclusion And Recommendations}

Nursing students were improving the level of knowledge and practices with regard to CPR after training. The nursing curriculum should lay more emphasis on the nurses to learn about different techniques of CPR. Continuing education should be conducted on regular after employment to prevent the loss of knowledge and practices

\section{References}

[1] Ackermann AD. (2009): Investigation of learning outcomes for the acquisition and retention of CPR knowledge and skills learned with the use of high-fidelity simulation. Clin Simul Nurs. Available at http://dx.doi.org/doi:10.1016/ j.ecns..05.002.

[2] American Heart Association (2013): Cardiac arrest statistics. American Heart Association. Retrieved from http://www.heart.org/HEARTORG/General/Cardiac-Arrest-Statistics_UCM_448311_Article.jsp., January 17

[3] Anne S , Oteng R.,Redman R., Lapham J., Bam V.,Dzomecku V ., Yakubu J., Tagoe N., and Donkor P.,(2014): Development of an emergency nursing training curriculum in Ghana Received in revised form 6 February 2014 Accepted 10 February .

[4] Aruna C.G. (2012): A quasi experimental study to assess the effectiveness of self instructional module regarding the techniques of resuscitation among staff nurses in selected hospitals at Bangalore. A dissertation submitted to the Rajiv Gandhi University of Health Sciences, Bangalore, Karnataka, in the partial fulfillment of requirements for the degree of Master of Science in pediatric nursing 2010-2012.

[5] Ashley E. , Lauren E. , Angela I, and Martha A(.2012):Using high-fidelity simulation to bridge clinical and classroom learning in undergraduate pediatric nursing. Accepted 16 January 2012 (C) 2012 Elsevier Ltd. All rights reserved.

[6] Baillie, L., \& Curzio, J. (2009): Students' and facilitators' per-ceptions of simulation in practice learning. Nurse Education in Practice, 9(5), 297-306.

[7] Beauchesne, M., \& Douglas, B., (2011): Simulation: Enhancing Pediatric, Advanced Practice Nursing Education. Newborn and Infant Nursing Reviews. 11 (1), 28-34.

[8] Benner, P., Sutphen, M., Leonard, V., Day, L., (2010): Educating Nurses: A Call for Radical Transformation. The Carnegie Foundation for the Advancement of Teaching, Standford, CA.

[9] Bergman, S., Deckelbaum, D., Lett, R., Haas, B., Demyttenaere, S., Munthali, V., et al., (2008):. Assessing the impact of the trauma team training program in Tanzania. The Journal of Trauma 65, 879-883.

[10] Broomfield, R. (1996): A quasi-experimental research to investigate the retention of basic cardiopulmonary resuscitation skills and knowledge by qualified nurses following a course in professional development. Journal of Advanced Nursing, 23, $1016-1023$.

[11] Dascher K D. ,( 2015): TEAMWORK DURING CARDIOPULMONARY RESUSCITATIONS AT A RURAL MINNESOTA HOSPITAL . In Partial Fulfillment of the Requirements for the Degree of DOCTOR OF NURSING PRACTICE March 2015

[12] Devlin M. (1999): An evaluative study of the basic life support psychomotor skills of nurses in an independent hospital. J Clin Nurs 1999;8:201-5.

[13] Einspruch EL, Lynch B, Aufderheide TP, Nichol G, Becker L.(2007): Retention of CPR skills learned in a traditional AHA Heartsaver course versus 30-min video self-training: a controlled randomized study. Resuscitation. 2007; 74:476-86. [PubMed: 17442479]

[14] Hardcastle, T.C., Oteng, R., (2011): Trauma care in Africa: triumphs and challenges. African Journal of Emergency Medicine 1, 53-54.

[15] Hunt, E. A., Fiedor-Hamilton, M., \& Eppich, W. J. (2008): Resus-citation education: Narrowing the gap between evidence-based resuscitation guidelines and performance using best educational practices. Pediatric Clinics of North America, 55(4), 1025-1250.

[16] Kardong-Edgren S, Adamson KA. (2009): BSN medical-surgical student ability to perform CPR in a simulation: recommendations and implications. Clin Simul Nurs;5:e79-83.

[17] Kardong-Edgren, S. E., Oermann, M. H., Odom-Maryon, T., \& Ha, Y. (2010): Comparison of two instructional modalities for nursing student CPR skill acquisition Resuscitation, 81(8), 1019-1024.

[18] Liaw, S. Y., Chan, S. W., Scherpbier, A., Rethans, J. J., \& Pua, G. G. (2012): Recognizing, responding to and reporting patient deterioration: Transferring simulation learning to patient care settings. Resuscitation, 83(3), 395-398.

[19] Liaw, S. Y., Scherpbier, A., Rethans, J. J., \& Klainin-Yobas, P. (2011): Assessment for simulation learning outcomes: A comparison of knowledge and self-reported confidence with observed clinical performance. Nurse Education Today, http://dx.doi.org/10.1016/j.nedt

[20] Liebermann M, Golberg N, Mulder D, Sampalis J. (2000): Teaching cardiopulmonary resuscitation to CEGEP students in quebec - a pilot project. Resuscitation.; 47:249-257.

[21] Lima SG, Macedo LA, Vidal LM, Oliveira SA, MPB. (2009): Permanent education in BLS and ACLS: Impact on the knowledge of nursing professionals. Arquivos Brasileiros de Cardiologia.;93:6-10.

[22] London, J.A., Mock, C.N., Quansah, R.E., Abantanga, F.A., Jurkovich, G.J., (2001): Priorities for improving hospital-based trauma care in an African city. The Journal of Trauma and Acute Care Surgery 51, 747-753.

[23] Madden C. (2006): Undergraduate nursing students' acquisition and retention of CPR knowledge and skills. Nurs Educ Today. 2006;26(3):218-227.

[24] Mäkinen, M., Axelsson, A., Castrén, M., Nurmi, J., Lankinen, I., \& Niemi-Murola, L. (2010): Assessment of CPR-D skills of nursing students in two institutions: Reality versus recom-mendations in the guidelines. European Journal of Emergency Medicine, 17(4), 237-239. http://dx.doi.org/10.1097/MEJ. 0b013e328331471b

[25] Marzooq H, \& Lyneham J. (2009): Cardiopulmonary resuscitation knowledge among nurses working in Bahrain. Intr J Nur Prac;15(4):294-302 
[26] McGaghie, W. C., Issenberg, S. B., Cohen, E. R., Barsuk, J. H., \& Wayne, D. B. (2011): Does simulation-based medical edu-cation with deliberate practice yield better results than traditional clinical education? A meta-analytic compara-tive review of the evidence. Academic Medicine, 86(6), 706-711.

[27] McKenna, L., Bogossian, F., Hall, H., Brady, S., Fox-Young, S., \& Cooper, S. (2011): Is simulation a substitute for real life clinical experience in midwifery? A qualitative examination of percep-tions of educational leaders. Nurse Education Today, 31(7), 682686.

[28] Meyer, M. N., Connors, H., Hou, Q., \& Gajewski, B. (2011): The effect of simulation on clinical performance: A junior nursing student clinical comparison study. Simulation in Healthcare, 6(5), $269-277$.

[29] Miró O, Escalada X, Jiménez-Fábrega X, Díaz N, Sanclemente G, Gómez X, Sánchez M.( 2008): Cardiopulmonary resuscitation programme for secondary schools (PROCES);. Conclusions after 5 years. Available:http://www.semes.org/revista/vol 20_4/3_ing.pdf

[30] Mokhtari Nori J, Saghafinia M, Motamedi K and Hosseini K (2012): CPR Training for Nurses: How often Is It Necessary? Iran Red Crescent Med J; 14(2):104-107

[31] Na, JU.; Sim, MS.; Jo, IJ.; Song, HG.; Song, KJ.( 2011): Basic life support skill retention of medical interns and the effect of clinical experience of cardiopulmonary resuscitation. Emerg Med J. 2011.

[32] Nyman J, \& Sihvonen M.(2000): Cardiopulmonary resuscitation in nurses and nursing students. Resuscitation;47(2):179- 184.

[33] Oermann M, Kardong-Edgren S, Odom-Maryon T. (2011): Effects of monthly practice on nursing students' CPR psychomotor skills performance. Resuscitation.;82:447 453.

[34] Parker, R.A., McNeill, J.A., Pelayo, L.W., Goei, K., Howard, J., Gunter, D., (2011): Pediatric clinical simulation: a pilot project. Journal of Nursing Education 50 (2), p105-p111.

[35] Pelaccia, T., Delplancq, H., Triby, E., Bartier, J. C., Leman, C., \& Dupeyron, J. P. (2009): Impact of training periods in the emergency department on the motivation of health care students to learn. Medical Education, 43(5), 462-469.

[36] Peter A., *, Robert M., Billy T, Andrew P., Nicole S, John R., Amanda, Andrew M., Kasey K., Dana E. Nilesh, Sharon Y., Loeto M, and Vinay M. (2012): Training hospital providers in basic CPR skills in Botswana: Acquisition, retention and impact of novel training techniques. Resuscitation. 2012 December ; 83(12): 1484-1490. doi:10.1016/j.resuscitation.2012.04.014.

[37] Roh Y S, and Issenberg B.(2014): Effects of an integrated simulation-based resuscitation skills training with clinicalpracticum on mastery learning andself-efficacy in nursing students. 1322-7696/@ 2014 Australian College of Nursing Ltd. Published by Elsevier Ltd.

[38] Roppolo LP, Pepe PE, Campbell L, et al (2007):. Prospective, randomized trial of the effectiveness and retention of 30-min layperson training for cardiopulmonary resuscitation and automated external defibrillators: The American Airlines Study. Resuscitation.; 74:276-85.

[39] Shahrakivahed, A., Masinaienezhad, N, Shahdadi, H., Arbabisarjou A., Asadibidmeshki, E. Heydari, M. (2015): The Effect of CPR Workshop on the Nurses' Level of Knowledge and Skill Vol. 8 No. 108

[40] Smith KK, Gilcreast D, Pierce K.(2008): Evaluation of staff's retention of ACLS and BLS skills.Resuscitation; 78:59-65.

[41] Spooner BB, Fallaha JF, Kocierz L, Smith CM, Smith SCL, Perkins GD.(2007): An evaluation of objective feedback in basic life support (BLS) training. Resuscitation ; 73:417-24.

[42] Stewart, M., Kennedy, N., Cuene-Grandidier, H., (2010): Undergraduate interprofessional education using high-fidelity paediatric simulation. The Clinical Teacher 7 (2), p90-p96.

[43] Sutton RM, Niles D, Meaney PA, et al.(2011): Low-dose, high-frequency CPR training improves skill retention of in-hospital pediatric providers. Pediatrics. 2011; 128:e145-51. [PubMed: 21646262]

[44] Sutton, R. M., Nadkarni, V., \& Abella, B. S. (2012): Putting it all together to improve resuscitation quality. Emergency Medicine Clinics of North America, 30(1), 105-122.

[45] Turner, N. M., Dierselhuis, M. P., Draaisma, J. M., \& ten Cate, O. T. (2007): The effect of the advanced pediatric life support course on perceived self-efficacy and use of resuscitation skills. Resus-citation, 73(3), 430 - 436

[46] Van Cleave, J., Gortmaker, S., Perrin, J., (2010): Dynamics of obesity and chronic health conditions among children and youth. JAMA 303 (7), 623-630.

[47] Wayne, D. B., Butter, J., Siddall, V. J., Fudala, M. J., Wade, L. D., Feinglass, J., et al. (2006): Mastery learning of advanced cardiac life support skills by internal medicine residents using simulation technology and deliberate practice. Journal of General Internal Medicine, 21(3), 251-256.

[48] Wayne, D. B., Butter, J., Siddall, V. J., Fudala, M., Lindquist, L., Feinglass, J., et al. (2005): Simulation-based training of internal medicine residents in advanced cardiac life support protocols: A randomized trial. Teaching and Learning in Medicine, 17, 202208.

[49] Wolf, L., Brysiewicz, P., LoBue, N., Heyns, T., Bell, S.A., Coetzee, I., et al., (2012): Developing a framework for emergency nursing practice in Africa. African Journal of Emergency Medicine 2, 174-181.

[50] Wulf, G., Shea, C., \& Lewthwaite, R. (2010): Motor skill learning and performance: A review of influential factors. Medical Education, 44, 75-84.

[51] Yildirim O. G, Celik Oyur G.(2008): Investigation of intensive care nurses' knowledge on basic life support. J Ege University School of Nursing. 24(3):45-58. 